\title{
English Language Learners, Labels, Purposes, Standard English, Whiteness, Deficit Views, and Unproblematic Framings: Toward Southern Decoloniality
}

\author{
Chaka Chaka \\ University of South Africa \\ chakachaka8@gmail.com
}

\begin{abstract}
This paper argues for revisiting ways in which English Language Learners (ELLs), and the learner labels attributed to them, are negatively, racially, and pathologically framed and constructed based on, putatively, their English language competence, or their lack of it. It contends that this framing tends to give rise to a raciolinguistic profiling of these learners, as they end up being classified by their race, pan-ethnicity, nationality, immigrant/refugee status, regionality, and at times, by their skin color, in addition to their language abilities. This raciolinguistic framing often engenders other framings such as White, deficit, and poverty framings, and sub-framings like an othering framing (e.g., the racial others and the linguistic others). These framings, together with the normative ways in which ELLs' language problems are constructed, have been characterized in this paper as misframings. Additionally, employing southern decoloniality, the paper problematizes and critiques the way ELLs are constructed and labeled, and the appropriation of Standard English (SE) as the sole touchstone of acceptable English in the midst of the other varieties of SE and of pluriversal speakers of English. Finally, the paper calls for the provincialization/localization or the deparochialization of English in keeping with its southern decolonial approach.
\end{abstract}

\section{Introduction}

English language teaching (ELT) literature abounds with labels ascribed to English language learners (Aguayo, 2020; Byfield, 2019; Flores \& Rosa, 2015; Flores et al., 1991; Hernandez, 2017; Mitchell, 2013; Nguyen, 2021; Umansky, 2016; Umansky \& Dumont, 2021). The phenomenon of labeling such learners, which is also known as learner classification (Abedi, 2008; Umansky, 2016), is rooted in the history and legacy of ELT itself as a field of study. It is a phenomenon employed to frame the levels of proficiency, fluency, and mastery of the English language that such learners display in spoken and written English. It is also, in a way, the type of classification used to refer to and to depict the brand of English these learners speak and write. In this context, it is common knowledge that within the ELT arena, and within the broader educational canvas, learner labels are ascribed to learners for whom English is not a home or a first language. Aguayo (2020) aptly captures this point thus: "Currently, the English Learner (EL) label is found in every facet of education concerning learners with home languages other than English" (p. ii).

Such learner labels are often applied to English language learners (ELLs) belonging to racial groups such as: Africans (often used concurrently with Blacks); African Americans; Latinos/Latinx; Chinese; Japanese; Koreans; Taiwanese; Filipinos; Thai; Vietnamese; Cambodians; Samoans; Native Americans; Aborigines; etc. (Carey, 2014; Flores et al., 1991; Licea, 2020; McKay et al., 2020; Mitchell, 2013). From another disciplinary angle, these 
language speaker labels resonate with “"black,' Chicano/a, Native American, and Asian American literary traditions" (Keating, 1995, p. 903), which are often contrasted with "“white' literary traditions" (p. 903). In the main, then, these learner labels are directed at and reserved for these multiple and diverse learners because their English is deemed to deviate from Standard English. The latter is, of course, based on monoglossic/monolinguistic ideologies and monoepistemologies of language (Bacon, 2017; Feagin, 2010; Kubota, 2020; Ortega, 2019; Von Esch et al., 2020). What the use of these labels and those who use them fail to do is interrogate, problematize, and critique: learner labels and their purposes (Aguayo, 2020; Pica-Smith \& Veloria, 2012; Umansky, 2016); the grounding and embeddedness of these learner labels in Standard English and in Whiteness (Aguayo, 2020; Ortega, 2019; Schornack, 2019; Von Esch et al., 2020; Wheeler, 2016); the association of ELLs with deficit views (Carey, 2014; Cunningham, 2019; Dudley-Marling \& Lucas, 2009; Hogarth, 2017; Jones, 2013; Nguyen, 2021); the intersection of ELLs and ELL labels with race, racism, language, and linguicism (linguistic racism) (Bacon, 2017; de Jesus Ferreira, 2007; Morita-Mullaney, 2018; Viesca, 2013; Von Esch et al., 2020); and unproblematic framings of ELLs (Flores et al., 1991; Gutiérrez \& Orellana, 2006; Mitchell, 2013). The current paper intends problematizing and critiquing all of these areas pertaining to ELLs. It does so by focusing on a diverse body of research which, on the one hand, advocates such a learner labeling phenomenon and normatively constructs ELLs, and which, on the other hand, critiques this learner labeling phenomenon and challenges a normative construction of ELLs. The paper also highlights gaps in current research dealing with ELL labeling. In addition, it offers instances of English language and views of ELLs as documented in examples from the United States (the U.S.). More significantly, it offers southern decoloniality as an alternative way through which to theorize about and frame ELLs.

\section{Learner Labels and Their Purposes}

Learner labels, and especially ELL labels, serve a specific purpose. Otherwise, there would be no reason for them to exist or to be appropriated. While there are multiple reasons for labeling ELLs, two cardinal reasons for such a labeling practice are worth mentioning. The first reason has to do with the normative practice of fixing and remediating the presumed linguistic deficiencies of ELLs. This practice is rooted in and undergirded by deficit assumptions often attributed to ELLs. It feeds into a historically, racialized rhetoric associated with English-Only movements (Aguayo, 2020; Pica-Smith \& Veloria, 2012) common in most monolingual, English-speaking countries such as the U.S. and the United Kingdom (the U.K.), and in most English-using postcolonies. The underlying assumption is that ELLs, because English is not their home language, are in need of special English language remediation programs. The latter will, it is often argued, enhance ELLs' English language proficiency, and by analogy, their academic career pathways, while diminishing their academic achievement and graduation gaps (Aguayo, 2020; Gutiérrez, 2005/2006; Gutiérrez \& Orellana, 2006; Nguyen, 2020; Umansky, 2016).

Most remediation models intended to fix ELLs' English language defects are inherently flawed. Firstly, they presume that all ELLs are a homogeneous group displaying invariable levels of English fluency (Shapiro, 2011) that has to be offered a one-size-fits-all linguistic remediation. However, a truism is that ELLs - even those belonging to the same ethnoracial group or to the same pan-ethnic group - are diverse learners with not only variable English fluency levels but also varying literacy levels. Secondly, most of these remediation models are predetermined: they

Journal of Contemporary Issues in Education, 2021, 16(2), pp. 21-37. 
offer predesigned remedy prior to diagnosis rather than offering bespoke language interventions to different ELLs.

The second reason remediation models are flawed is because they other ELLs, according to a belief that ELLs are different from dominant, monolingual English speakers. In this sense, models rely on the difference ideology, or on what Gutiérrez and Orellana (2006) refer to as genres of difference, which do exactly what they are intended to do: frame difference (e.g., multilingualism) as a pathology (Crumper et al., 2011; Grosfoguel, 2013; Mitchell, 2013) or characterize ELLs as linguistic others. Additionally, such models are driven by the essentialized and racialized notion of Whiteness. Whiteness adopts and appropriates a dominant and normalizing vantage point that frames and conceptualizes other racial groups differentially. It is a perpetuation of the "monoculture of the naturalization of differences" (Sousa Santos, 2014, p. 273), according to which social classifications and classical dichotomies such as "scientific culture/literary culture, scientific knowledge/traditional knowledge, man/woman ... civilized/primitive ... white/black, North/South, West/East" (p. 266) become naturalized, everyday normal occurrences. Moreover, the difference framing draws on Eurocentric metonymic reason, which valorizes dichotomies of parts within a whole (Sousa Santos, 2014), and in which the first term in each pair is evaluated positively, while the second term in each pair is evaluated negatively. In this way, ELL as a classificatory term employed to refer to other national originals or pan-ethnic/-racial groups, or to immigrant/refugee groups (Gutiérrez, 2005/2006; Gutiérrez \& Orellana, 2006), is framed dichotomously relative to dominant, monolingual English speakers, who are perceived to constitute a monolithic, homogeneous group. Needless to say, this depiction and identification of ELLs is short-sighted, deficit-driven, misguided, and racialized (Kubota, 2020; Kubota \& Lin, 2006; Mitchell, 2013).

\section{The Grounding and Embeddedness of ELL Labels in Standard English and in Whiteness}

ELL labels, the paper contends, are informed by and embedded in Standard English (SE). SE, which is a belief in the existence of a predictable, determinable, and universally acceptable set of rules governing spoken and written English (Bacon, 2017), serves as a normative benchmark against which all other varieties of English are judged. Any variety that diverges from the normative rules associated with spoken and written SE is judged to be deviant and inappropriate. This, too, applies to the varieties of English used by ELLs. Further, this development has spawned naturalized binary terms such as Standard English and non-Standard English. The former is often associated with native English speakers (NESs) and serves as a touchstone, while the latter is attributed to nonnative English speakers (NNESs), of whom ELLs are a part. However, as has been argued by some scholars (Bacon, 2017; Parakrama, 1995; Rosa, 2016; Silverstein, 1996; Von Esch et al., 2020), the ideology of SE has an aura of myth about it: while it is assumed to exist, its actual speakers cannot be traced to and located at any point on a geolinguistic map. Neither can a geolinguistic center be located. The only living romantic relic of $\mathrm{SE}$ is its attachment to Anglo-Saxonism, one manifestation of which is Anglo-Americanism. But even then, this is a distant, if not an elusive and romantic, rootage of SE.

Of course, there is British Standard English, and there is American Standard English. Of the two, which is the super-standard, and which is the subordinate standard? The English language purism jury has yet to make its pronouncement in this regard. Added to this is the fact that in either case, 
there is just not one standard variety, but more than just one. Godley et al. (2015) contend that there is a "myth that Standardized English is better and more grammatical than the language varieties spoken by many black and Latino students" (p. 43). The other point is that SE itself is embedded in the native speaker construct, the notion of a linguistic model based on native speaker norms (Bacon, 2017; Kubota \& Lin, 2006; Kumaravadivelu, 2016; Parakrama, 1995; Von Esch et al., 2020) that ELLs need to emulate. But as is the case with SE, the notion of the native speaker has its own polemics, and it is a contested terrain. For instance, in one of its crudest manifestations, the native speaker construct engenders and thrives in the essentialized and racialized polar terms such as: native speakerism $=$ Standard English speakerism $=$ Whiteness versus nonnative speakerism $=$ non-Standard English speakerism $=$ non-Whiteness (Kubota \& Lin, 2006; Silverstein, 1996; Von Esch et al., 2020). As argued earlier, these classical polar terms are predicated on Eurocentric metonymic logic. Therefore, equating the native speaker to Standard English is an ideological tendency that is oblivious to correct varieties of English used and spoken by people of color, as well as by those who are not necessarily natives as implied by the native speaker construct. The same applies to equating the native speaker to Whiteness: there are native speakers of English who are not White. So, this metonymic equation tends to erase native non-White speakers of English from existence. It is a practice that lends itself well to the "monoculture of logic of the dominant scale" (Sousa Santos, 2014, p. 274), according to which the primordial scale such as SE has the authority to render all possible scales (all non-standard forms of English) irrelevant (cf. Sousa Santos, 2014). The upshot of this dominant language scale is labeling non-Standard English speakers variably.

In a different but related context, Rosa (2016) posits two intersecting normative language practices in this regard: ideologies of language standardization and ideologies of languagelessness. Ideologies of language standardization always denigrate linguistic forms perceived to digress from prescribed norms, while ideologies of languagelessness delegitimize a person's or a group's existing linguistic capacity. The former is related to the "culture of monoglot Standard" (Silverstein, 1996, p. 284), which is akin to the monoculture of logic of the dominant scale as mentioned above, and which is informed by various "metaphors of linguistic hegemony" (p. 284). This culture of monoglot Standard has its roots in colonial modernity ideologies that privilege the primacy of one-language, one-state, and one-nation over multilingual states and pluriracial nations. This ideal, romantic, monolingual, and monocultural statehood and nationhood has given rise to the "coloniality of language" (Veronelli, 2015, p. 113; also see Rosa, 2016, p. 164), one example of which is English and its attendant Standard English. In this way, any practice that conceptualizes language from racial frames through inclusion into and through exclusion from Standard English runs the risk of commingling ideologies of language standardization and ideologies of languagelessness.

Again, ELL labels are, the paper argues, grounded in and informed by Whiteness. Whiteness (also White privilege [Viesca, 2013]) is employed here as an ideology, as an analytic standpoint, and as a racial frame (Chubbuck, 2004; DuBois, 1973; Dutta et al., 2021; Frankenberg, 1993; Gutiérrez, 2005/2006; Keating, 1995; McIntosh, 1989; Schornack, 2019) more than just as a construct. There are two levels at which it operates: naturalization and innocence. That is, Whiteness naturalizes itself (Whiteness), while it is innocent or ignorant of anything such as Whiteness and non-Whiteness (Gotanda, 2004; Gutiérrez, 2005/2006). Gutiérrez (2005/2006) aptly captures White innocence thus:

Journal of Contemporary Issues in Education, 2021, 16(2), pp. 21-37. 
Put simply, a white innocence analysis involves naming the framework that has been naturalized and that allows the dominant subject position to remain "innocent" - to claim, "Who knew?" while sustaining the dominant framework and blocking opportunities for non-dominant groups. (p. 227)

In one related instance, Chubbuck (2004) maintains that Whiteness embodies attitudes, ideologies, and practices of racism. In another, Schornack (2019) identifies four pillars of Whiteness: White gaze, dominance, common sense, and invisibility. She also argues that Whiteness is the manner in which the architecture and infrastructure of White cultural hegemony and White supremacy are enacted on a daily basis. The current paper concurs with the views of Whiteness articulated by both Chubbuck (2004) and Schornack (2019). In addition, the paper asserts that Whiteness is the lifeline of Eurocentrism, and that it is also implicated in Westernness and in the White gaze (Frankenberg, 1993). Given this brief characterization of Whiteness, the paper contends that Whiteness is behind the labeling and stereotypification of ELLs and other language learners for whom English is not a home language. It does so through the triple posture of innocence, neutrality, and color-blindness. By adopting this triple posture, Whiteness is often complicit in attaching labels to such learners, as well as in stereotyping and framing them as such via binary oppositional constructions. In so doing, Whiteness privileges White, European, native speaker, Standard English, while invisibilizing and othering English varieties of ELLs through the White gaze. However, Whiteness itself operates invisibly even though it has a universal presence. Keating (1995) refers to this subtle invisibility of Whiteness as its "pervasive nonpresence" (p. 904) and "unmarked superiority" (p. 904; also see Solomon et al., 2005, p. 148). This subtle invisibility is aided and abetted by the ubiquitous innocence that Whiteness assumes wherever it operates. Elsewhere, Pimentel (2011) aptly captures this invisible operation of Whiteness: "Insofar as society produces Blackness and brownness as inferior, the myth of Whiteness as superior is sustained, and vice versa. Uniquely, however, Whiteness often maintains its power through silence and invisibility" (p. 341).

\section{ELLs and Their Putative Association with Deficit Views}

ELLs mostly tend to be associated with deficit views. The latter are variously known as deficit discourses (Baroutsis \& Woods, 2018; Dudley-Marling, 2015); deficit theories (Jones, 2013); deficit perspectives (Gutiérrez \& Orellana, 2006); deficit thinking (Davis \& Museus, 2019); deficit-model thinking (Cunningham, 2019; Takeuchi, 2021); deficit gaze (Dudley-Marling, 2007); language deficit (Grainger \& Jones, 2013); linguistic deficit/the linguistics of deficit (Jones, 2013); linguistic deficiency (Cunningham, 2019); discourse of cultural deprivation (Dudley-Marling, 2007); deficit constructions (Gutiérrez, 2005/2006); deficit frames (Byfield, 2019); deficit mindsets (Carey, 2014); or deficit ideologies (Bacon, 2017). And, the list continues! This endless list underscores part of the contention of the present paper that ELLs, and their attendant linguistic abilities are constantly associated with deficit models. These deficit models are, as depicted here, multiply constructed, even though the common denominator of these multiple constructions is deficit.

The deficit models through which ELLs are perennially constructed are steeped in the belief that these learners' linguistic deficiencies are correlated with and are determined by such learners' 
equally deficient, if not deprived, social, cultural, and linguistic backgrounds (Baroutsis \& Woods, 2018; Dudley-Marling, 2007, 2015; Jones, 2013). Notwithstanding the fact that scholars cited in the preceding sentence and many more, such as Gorski (2011), Patton and Museus (2019), Pica-Smith and Veloria (2012), and Valencia (1997), have shown the theoretical implausibility and the shaky foundations of deficit views in varying degrees, such views nonetheless continue to persist. In fact, Dudley-Marling (2015) posits that despite a decades-long sustained critique of deficit thinking that pathologizes the language abilities and cultures of speakers from poverty-stricken living conditions, such thinking still persists. She further advances her viewpoint as follows: "A half-century of critique has failed to diminish the power of deficit thinking" (n.p.; also see Rosa \& Flores, 2017, p. 102). Even though Dudley-Marling characterizes this as "the resilience of deficit thinking" (n.p.), she regards this persistence as the hauteur and superbia of deficit thinking that is undergirded by Whiteness, metonymic reason, and the monoculture of logic of the dominant scale, all of which manifest themselves in the monoglot Standard English as argued earlier.

There is another genre of deficit thinking that links ELLs and their purported language deficiencies to the culture of poverty (Payne, 2005; see also Dudley-Marling, 2007, 2015; Kuchirko, 2019; Patton \& Museus, 2019; Pica-Smith \& Veloria, 2012). Championed and advocated by Payne (2005), amongst others (Hart \& Risley, 1995), some of the crude cardinal assertions of the culture-of-poverty orientation are: poor children and their poor families are to blame for their pathological culture of poverty; there are hidden rules, especially hidden middle class rules, that the poor need to learn for them to get out of their poverty; and for some of the poor people, poverty is a personal choice as they are disinclined to learn the hidden rules (Dudley-Marling, 2015; also see Kuchirko, 2019). Unbundled, these cardinal assertions embody a vicious cycle: poverty (socioeconomic and cultural poverty) engenders linguistic poverty/linguistic deprivation, and the latter (linguistic poverty/linguistic deprivation) is embedded in socioeconomic and cultural poverty. This vicious cycle is self-perpetuating in that the poor, and by extension ELLs, choose not to get out of poverty. The import of the culture of poverty for ELLs is that they have linguistic deficiencies because of their poor socioeconomic and cultural conditions. But their linguistic deficiencies will not diminish because ELLs opt not to disentangle themselves from their poor socioeconomic and cultural backgrounds.

\section{Intersection of ELLs and ELL Labels with Race, Racism, Language, and Linguicism}

There is, this paper further contends, an intersectionality of ELLs and the phenomenon of ELL labeling with race, racism, language, and linguicism. One only has to look at the racial and demographic profiling of ELLs - and other language learners - for one to realize to whom and to which racial demographics ELL labels and other language labels are often directed. As pointed out earlier, such learner labels are attributed mostly to Africans/Blacks; African Americans (also referenced as Blacks); Latinos/Latinx; Chinese; Japanese; Koreans; Taiwanese; Filipinos; Thai; Vietnamese; Cambodians; Asian Pacifics; Native Americans; Aborigines; and/or immigrant/refugee groups (Carey, 2014; Flores et al., 1991; Kubota, 2020; Kubota \& Lin, 2006; Licea, 2020; McKay et al., 2020; Viesca, 2013; Von Esch et al., 2020). In fact, the list is endless. In some instances, particularly in the global North, ELL labels are used to refer to languageminoritized groups. In other instances, especially in the global South, such learner labels are applied to language-majoritized groups, particularly pluri-ethnic, multilingual groups. Hardly 
ever are such learner labels appropriated to refer to mainstream, White, native English learners even when their forms or varieties of English are non-standard. This particular race-based construction of ELL labels reflects the interplay of race and language in English language teaching (ELT). Furthermore, it embodies and underscores the intersectionality of race/color, racism, language, and linguicism that is embedded in the English language teaching and learning ecosystem, especially when this ecosystem becomes invisibly and subliminally raced and racialized.

Additionally, construction of ELL labels evinces invisible and subliminal racial frames through which English language teaching and learning is viewed, and through which ELLs, whether as language-minoritized groups or whether as language-majoritized groups, are perennially constructed and pathologized as "racial Others" (Von Esch et al., 2020, p. 393; also see Solomon et al., 2005, p. 147). Emphasizing the embeddedness of race, racialization, and racism in the field of teaching English to speakers of other languages (TESOL), and by implication in English language teaching and learning, Kubota and Lin (2006) aver: "The idea of race, racialization, and racism are inescapable topics that arise in the contact zones created by teaching English worldwide" (p. 471). Unfortunately, though, these are the topics that certain mainstream ELT avoids tackling head-on (Alim et al., 2016; Bacon, 2017; Carey, 2014; de Jesus Ferreira, 2007; Godley et al., 2015; Gorski, 2011; Kubota, 2020; Kumaravadivelu, 2016) but which have to be constantly highlighted. In a different but related context, Viesca (2013) maintains that both racism and linguicism need to be unearthed from their surreal obscurity and brought under a magnifying glass.

In a similar vein, De Costa (2020) opines that linguistic racism tends to amplify when speakers are multilinguals, and when these speakers have to straddle different language varieties and various languages. He also argues that often linguistic racism becomes conflated with a speaker's skin color, and that this is a linguistic reality with which people of color have to wrestle on a daily basis, especially when they style-shift between vernacular English and Standard English. To this end, he illustrates his view by pointing out that Michelle Obama (former U.S. First Lady) was once pilloried for her "poor ebonic English" (p. 833) (her nonstandard English) or for styleshifting between Standard American English and African American English, while her Standard American English was simply ignored. Moreover, he makes an observation that Barack Obama (former U.S. president) is frequently constructed "as being 'articulate while black" (p. 833). Can the converse, being articulate while white, apply here? Improbable! So, in appropriating ELL labels to refer to ELLs in the field of English language teaching and learning - and in that of TESOL - there is a constant conflation of race, racism, language, and linguicism.

\section{Unproblematic Framings of ELLs}

The picture to be painted here is that of the problems of the problem learners. This is part of the dominant framings through which ELLs and the multiple labels apportioned to them are often constructed. These framings are couched in Whiteness, racial discrimination, linguistic racism, and mono-languaging (Flores \& Rosa, 2015; Gutiérrez, 2005/2006; Gutiérrez \& Orellana, 2006; Kubota, 2020; Solomon et al., 2005; Takeuchi, 2021; Von Esch et al., 2020). They are constructed variously as a White frame, a racial frame, a deficit frame, and an othering frame, all of which add to a broader raciolinguistic profiling of ELLs. A White frame is grounded on 
Whiteness as discussed earlier. Mostly, it constructs ELLs as non-Whites whose English language competence (or lack thereof) is judged against that of White, native speakers. This is a point that Obeyesekere (2017) poignantly highlights when she insists that Whiteness "acts as the absent presence, or hidden referent against which all other colours are measured as a form of deviance" (p. 11). In the case of ELLs, their non-Whiteness is one of the key criteria that simplistically qualifies their English language competence to be deviant. Allied to a White frame is a racial framing. This framing tends to racialize the English language competence of ELLs. It operates institutionally and globally through institutions (e.g., schools and universities), ELT textbooks, ELL/ELT research, English language teachers, and the mass media (De Costa, 2020; Feagin, 2010; Kubota, 2020; Kubota \& Lin, 2006; Kumaravadivelu, 2016; Von Esch et al., 2020). It also functions so through maintaining "old geographies of knowledge" (Dei, 2017, p. xii).

For its part, a deficit frame operates by constructing ELLs and their English varieties as either deficient, poor, deviant, or nonstandard. Lastly, an othering frame conceptualizes ELLs as racial others, or pathological others. It views the English varieties of ELLs as evincing pathological forms that are only unique to ELLs and not to native speakers. These four framings, this paper argues, intersect with the genres of difference (Gutiérrez, 2005/2006; Gutiérrez \& Orellana, 2006) or with the ideology of differences. So, as pointed out above, these are the problems of the problem learners (ELLs) that are presented as faits accomplis but which this section has attempted to highlight and problematize.

Elsewhere, Gutiérrez (2005/2006) and Gutiérrez and Orellana (2006) contend that research into ELLs is stymied by how it frames its problems, locates those problems, poses those problems, and names/formulate those problems, as well as the standpoints it adopts in framing those problems. Gutiérrez and Orellana (2006) put a cherry on top by posing: "Whose problem is it? For whom is it a problem? What other problems might we identify if we began from different vantage points?" (p. 118).

\section{Instances of English Language and Views of ELLs - Some Documented Examples from the U.S.}

In this section, instances of English language and views of ELLs, especially as documented examples from the U.S., are presented. The key reasons for focusing on the U.S. are: it attracts a high number of diverse ELLs globally compared to other countries; for it the issue of ELLs is a high-stakes affair, which has multiple iterations such as word gap, language gap, or achievement gap (Kuchirko, 2019; Nguyen, 2021) at both school and post-secondary education levels, and for education policy makers (Gunderson, 2020; Marsh, 2018; Nguyen, 2021; Shapiro, 2014), all of which feed into deficit thinking models; it has the most documented research instances on ELLs (Abedi, 2008; Crumpler et al., 2011; Kuchirko, 2019; Marsh, 2018); and it is a place in which the deficit discourse of ELLs affects such learners almost on a daily basis (Shapiro, 2014). Excerpt 1 below depicts one instance through which ELLs are viewed in the U.S., particularly at a community college level:

The demographics of our colleges are changing drastically today as the number of nonnative speakers of English enrolling in community colleges continues to rise. Initially, 
there seemed to be a homogeneity despite the ethnic diversity. International students often came to the United States to study and returned to their country when they completed their studies. Over time, college-age and adult immigrants began to out-number these international students. As the adolescent children of the adult immigrants finished high school in their new country and began to enter the college, another new dimension was added. Many of these learners or high school graduates are entering American colleges while still learning English. These students are referred to as Generation 1.5 students because they have characteristics of both first- and second-generation immigrants ... (Excerpt 1, Singhal, 2004, p. 1).

There are three salient points in this excerpt. The first is the changing demographics of nonnative speakers of English (or ELLs) entering colleges, who were, initially, thought to be homogeneous despite their ethnic diversity. The nature of the ethnic diversity of these ELLs is not mentioned nor are their nationalities specified. Despite these apparent omissions, it is inconceivable how they were expected to be homogenous when they had ethnic diversity. The second salient point is how these burgeoning ELLs were now appearing to outnumber international students, whose ethnic and national origins could not have been homogeneous. The third salient point is that these are referred to as Generation 1.5 students as they display linguistic features of both firstand second-generation immigrants. While the racial and national affiliations of these immigrants are not mentioned, it is common knowledge that most nationalities that immigrate to the U.S. are from countries nearer to it. Notwithstanding this, one central aspect of the third point is yet another labeling accorded these ELLs, Generation 1.5 students, a feature that adds to multiple labels ascribed to ELLs.

Some may not even be able to communicate fully with their family members. Many of these students may become "dual nonnative speakers" because they are not fully proficient in either their L1 or their L2-English. Finally, while they may see themselves as native-English speakers because of their social and verbal skills, they are often less skilled in the academic skills necessary for college-level courses and the cognitive and linguistic demands of discipline-specific academic classes in English language institutions of higher learning (Excerpt 2, Singhal, 2004, p. 2).

Another central aspect of the third point, which is captured in Excerpt 2, is that Generation 1.5 students are characterized as dual nonnative speakers who are neither fully proficient in their L1 nor in their L2. In this precarious linguistic duality, they are not sufficiently equipped with college-level academic skills nor do they possess requisite discipline-specific cognitive and linguistic skills. Flores et al. (2015) point out that terms like semilingual, languageless, nonnons, and clinically disfluent have been used to characterize Generation 1.5 students, a further element that contributes to their multiple labels.

In other instances, especially at a school level, ELLs are given vocabulary tests such as the one below, to which there are two sample responses:

Directions: Choose SIX vocabulary words from the Monster Word Bank and write a grammatically correct sentence, which shows me that you know the meaning of the word, for each one (1 pt. each). You may only use the form of the word shown below. 
Monster Word Bank

Conspicuous ( $a d j)$; Nonchalantly ( $a d v)$; Orneriness $(n)$; Significance (n); Riffle (v);

Provocation (n); Gaping (adj); Eulogy (n); Scamper(v); Beckon (v); Mural (n)

Response One $\left(9^{\text {th }}\right.$ grader $)$

1. I have a mural in my house in the living room.

2. My cuzin has a gaping between her to bottom teeth which looks nice on her.

3. I Beckon to not tell a soul about the house party last Sat.

4. My auntie had a Provocation to drink whenever someone gets her mad.

5. My dad had a Riffle when he was in the millitary.

6. I have a significance of awards of good behavior.

Response Two $\left(9^{\text {th }}\right.$ grader $)$

1. The happy dog scamper through the field.

2. There were plenty of mural at the museum.

3. The significance of basketball is teamwork.

4. In [Ms. H's] class I conspicuous to myself.

5. The teacher told me to riffle through all the pages.

6. When I was tired I sang nonchalantly (Excerpt 3, Viesca, 2012, pp. 8-9).

The sample two responses by two $9^{\text {th }}$ graders from multilingual backgrounds, as shown in the preceding excerpt, are conspicuous for their non-conformity to English grammatical forms and functions. Some of the areas of non-conformity are spelling, capitalization, parts of speech (Viesca, 2012), and grammatical well-formedness. While these grammatical aspects are easily detectable from these two sample responses, they highlight the problematic and mechanistic ways in which English language learning is sometimes approached. These problematic and mechanistic ways relate particularly to: grammatical prescriptivism and orthodoxy; teaching and testing grammar in a decontextualized manner; ignoring learners' existing linguistic repertoires as embedded in their multilanguages; applying one Standard English (SE) in the midst of many SE varieties; and delinking English grammar/English language from learners' lived experiences, from learners' sociocultural and politico-material conditions, and from existing dominant language ideologies. All these unproblematized multiple factors lend themselves easily to deficit language views together with their attendant multiple ELL labels.

Nonetheless, these deficit views have not been without challenges, nor have they been without a backlash from ELLs themselves. One classic case in which these deficit views have been challenged is that of a midsize refugee settlement in New England, whose high school students protested against annual standardized test scores that were published in one of the local newspapers (Shapiro, 2014). Some of the portions that the newspaper had published read as follows: "Annual standardized test scores ... show a yawning achievement gap between highincome and low-income students in the district. English language learners, many of whom are African refugees, have even lower scores" (p. 389). Brandishing placard with messages such as "End Racism," "Racial profiling kills," and "Unite and fight racism" (p. 389), students staged a 
protest against the newspaper article. When interviewed after the protest, one student contended that: "They made it clear in the newspaper like Africans was the reason [for low] scores. The kids that are from Africa did get mad, cause there's like Nepalese, there's like Vietnamese, like Asians and all that, and they only picked on the Africans. That like pissed everyone off' (p. 394). One cannot help but shudder at how, in the midst of this linguistic rage and repugnance, this test score protest degenerated into ethnicizing and racializing test scores by ELLs themselves, in their fight against language racism and language racialization.

\section{Southern Decoloniality}

Southern decoloniality is used here as a standpoint or a framing. Southernism refers to southern theory (Connell, 2007; Takayama et al., 2016), southern epistemologies (Sousa Santos, 2014), and southern perspectives (Heugh \& Stroud, 2018; Lazar, 2020; Pennycook \& Makoni, 2020; Takaki, 2020). For its part, decoloniality is employed as an approach in the same way as is articulated by Mignolo (2010), Nakata (2007), Tuhiwai Smith (1999), and wa Thiong'o (1986), among other scholars. Most importantly, southern decoloniality views the global South, together with theoretic-linguistic epistemes produced by its scholars, as a critical reference point in both the geopolitics and economy of knowledge production and circulation (Connell, 2007; Kloß, 2017; Lazar, 2020; Mignolo, 2010; Sousa Santos, 2014; Takayama et al., 2016). Additionally, it decolonizes, challenges, and critiques hegemonic, Northern-centric geopolitics of knowledge generation (see Lazar, 2020), even when this hegemonic knowledge production is perpetuated by scholars from the global South. Therefore, from a southern decolonial framing, not every scholar in the global North is a perpetuator of hegemonic, Northern-centric epistemologies. Neither is every scholar in the global South a critic of hegemonic, Western-centric epistemologies. Most importantly, a southern decolonial framing does not regard every scholar in the global South as an embracer of southern epistemologies (Kloß, 2017; Lazar, 2020; Moosavi, 2020).

Pertaining to ELLs, southern decoloniality critiques and deracializes learner labels appropriated to refer to ELLs. It advocates that race, racism, ethnicity (pan-ethnicity), nationality, and regionality should not serve as determinants for identifying and classifying ELLs as is currently the case. Racial classification of learners, which often culminates in racial stereotyping and racism, is incongruent not only with linguistic rights of such learners, but also with their human rights in a modern-day, posthuman, $21^{\text {st }}$ century society. Even in instances where remediation is deemed a necessary intervention for ELLs, such remediation should be bespoke and fit-forpurpose. It cannot just be a one-size-fits-all linguistic remediation that treats all ELLs as if they are one homogeneous grouping. If this is the case, then such a remediation is misguided, or it is rooted in outdated models.

The other factor that does not resonate with southern decoloniality is labeling ELLs according to the dictates of Standard English (SE). This constitutes a misframing of these learners as SE is not a static, idealized, abstract English spoken and used by ideal native speakers inhabiting a given geolinguistic location, and which is impervious to how other English speakers speak and use English. Why is it that when there are more nonnative English speakers than there are native English speakers that the rules of how to speak (and write) English are still determined by the hegemonic minority as opposed to the positive influences brought to English by its nonhegemonic majority? While speaking any language is not a majoritarian numbers game, surely 
common sense dictates that the ways and manners of speaking of the majority speakers should be taken into account when it comes to speaking and using that language. For southern decoloniality, as articulated in this paper, an SE that is quintessentially and rigidly based on White, native speakerism, to the total exclusion of non-White native speakers, is racially motivated. This is more so since there is not just one SE, but many varieties of SE. To this effect, the paper supports the provincialization/localization (see Borelli, Silvestre, \& Pessoa, 2020) of English, or the deparochialization (Chaka et al., 2017) of English.

Moreover, southern decoloniality is against associating ELLs and their language problems with deficit views and with the culture of poverty as discussed earlier. It argues that doing so is a misframing that is self-serving. It is like a researcher creating and hypothesizing deficits, linking them to participants (ELLs), and finding them as expected. Rather, a southern decolonial approach contends that ELLs' language problems be framed in a way that does not tie those problems to deficiencies, but in a way that foregrounds linguistic aspects in which ELLs excel, and how their other languages (their multilingual resources) can be tapped into to help enrich their English competence. In no way should ELLs' plurilanguages be reduced to the culture of poverty or be equated with deficits, especially when those who do so can hardly speak other languages than English itself. As argued earlier, the tendency of constructing problems (deficits) for problem learners (ELLs) results in discovering exactly those problems. So, for southern decoloniality, the manner in which researchers normatively frame (language) problems for ELLs needs a radical transformation and reframing, and an immense decolonization.

\section{Conclusion}

This paper has attempted to put a case for revisiting the ways in which ELLs, and the learner labels attributed to them, are negatively, racially, and pathologically framed and purportedly constructed based on their English language competence or lack. It argues that such framing tends to engender a raciolinguistic profiling of these learners, as they end up being profiled by their race, pan-ethnicity, nationality, immigrant/refugee status, regionality, and at times, by their skin color, in addition to their language abilities. This raciolinguistic framing often spawns other framings such as White, deficit, and poverty framings, and sub-framings like an othering framing (e.g., the racial others and the linguistic others). These framings, together with the normative ways in which ELLs' language problems are constructed, have been referred to in this paper as misframings. Finally, the paper has recommended southern decoloniality as a perspective, a standpoint, a framing, or an approach through which to theorize ELLs and the learner labels imputed to them. To this end, southern decoloniality problematizes and critiques: the way ELLs are constructed and labeled; the appropriation of Standard English (SE) as the sole determinant of Standard English in the midst of the other varieties of SE and of pluriversal speakers of English; and normative English linguistic remediation models. Lastly, the paper has called for the provincialization/localization or the deparochialization of English in line with its southern decolonial approach.

\section{References}

Abedi, J. (2008). Classification system for English language learners: Issues and recommendations. Educational Measurement: Issues and Practice, 27(3), 17-31. 
Aguayo, V.A. (2020). Life after the EL label: Conversations about identity, language, and race [Unpublished doctoral dissertation]. University of San Francisco. https://repository.usfca.edu/diss/522.

Alim, H.S., Rickford, J.R., \& Ball, A.F. (2016). Raciolinguistics: How language shapes our ideas about race. Oxford University Press.

Bacon, C.K. (2017). Dichotomies, dialects, and deficits: Confronting the "Standard English" myth in literacy and teacher education. Literacy Research: Theory, Method, and Practice, 66, 341-357. https://doi.org/10.1177/2381336917719255

Baroutsis, A., \& Woods, A. (2018). Children resisting deficit: What can children tell us about literate lives? Global Studies of Childhood, 8(4), 325-338. https://doi.org/10.1177/2043610618814842338

Borelli, J.D., V.P., Silvestre, V.P.V., \& Pessoa, R.R. (2020). Towards a decolonial language teacher education. Revista Brasileira de Linguistica Aplicada, 20(2), 301-324. http://dx.doi.org/10.1590/1984-6398202015468

Byfield, L. (2019). Labeling English learners: Teachers' perceptions and implications. International Journal of Education \& Literacy Studies, 7(4), 69-75. http://dx.doi.org/10.7575/aiac.ijels.v.7n.4p.69

Carey, R.L. (2014). A cultural analysis of the achievement gap discourse: Challenging the language and labels used in the work of school reform. Urban Education, 49(4), 440-468. https://doi.org/10.1177/0042085913507459

Chaka, C., Lephalala, M., \& Ngesi, N. (2017). English studies: Decolonisation, deparochialising knowledge and the null curriculum. Perspectives in Education, 35(2), 208-329. https://doi.org/10.18820/2519593x/pie.v35i2.16

Chubbuck, S.M. (2004). Whiteness enacted, whiteness disrupted: The complexity of personal congruence. American Educational Research Journal, 41(2), 301-333.

Connell, R. (2007). Southern Theory: The Global Dynamics of Knowledge in Social Science. Cambridge: Polity Press.

Crumpler, T.P., Handsfield, L.J., \& Dean, T.R. (2011). Constructing difference differently in language and literacy professional development. Research in the Teaching of English, 46(1), 55-91.

Cunningham, C. (2019). Terminological tussles: Taking issue with "English as an Additional Language" and "Languages Other Than English." Power and Education, 11(1), 121-128. https://doi.org/10.1177/1757743818806919

Patton Davis, L., \& Museus, S. (2019). What is deficit thinking? An analysis of conceptualizations of deficit thinking and implications for scholarly research. Currents, 1(1), 117-130. http://dx.doi.org/10.3998/currents.17387731.0001.110

De Costa, P.I. (2020) Linguistic racism: Its negative effects and why we need to contest it. International Journal of Bilingual Education and Bilingualism, 23(7), 833-837. https://doi.org/10.1080/13670050.2020.1783638

de Jesus Ferreira, A. (2007). What has race/ethnicity got to do with EFL teaching? Linguagem \& Ensino, 10(1), 211-233.

Dei, G.J.S. (2017). Foreword. In A. Abdulle, \& A.N. Obeyesekere (Eds.), New Framings on Anti-racism and Resistance (pp. ix-xiii). Sense Publishers.

DuBois, W.E.B. (1973). The education of Black people: Ten critiques, 1906-1960. University of Massachusetts Press.

Journal of Contemporary Issues in Education, 2021, 16(2), pp. 21-37. 
Dudley-Marling, C. (2007). Return of the deficit. Journal of Educational Controversy: An Interdisciplinary journal of Ideas, 2(1). https://cedar.wwu.edu/jec/vol2/iss 1/5/

Dudley-Marling, C. (2015). The resilience of deficit thinking. Journal of Teaching and Learning, 10(1). https://jtl.uwindsor.ca/index.php/jtl/article/view/4171

Dudley-Marling, C, \& Lucas, K. (2009). Pathologizing the language and culture of poor children. Language Arts, 86(5), 362-370.

Dutta, M., et al. (2021). Decolonizing open science: Southern interventions. Journal of Communication, 0(0), 1-24. https://doi.org/10.1093/joc/jqab027

Feagin, J.R. (2010). The white racial frame: Centuries of racial framing and counter-framing. Routledge.

Flores, N., \& Rosa, J. (2015). Undoing appropriateness: Raciolinguistic ideologies and language diversity in education. Harvard Educational Review, 85(2), 149-171.

Flores, B., Cousin, . T., \& Díaz, E. (1991). Transforming deficit myths about learning, language, and culture. Language Arts, 68(5), 369-379.

Flores, N., Kleyn, T., \& Menken, K. (2015). Looking holistically in a climate of partiality: identities of students labeled long-term English language learners. Journal of Language, Identity \& Education, 14(2), 113-132. https://doi.org/10.1080/15348458.2015.1019787

Frankenberg, R. (1993). White women, race matters: The social construction of whiteness. University of Minnesota Press.

Godley, A.J., Reaser, J., \& Moore, K.G. (2015). Pre-service English language arts teachers' development of critical language awareness for teaching. Linguistics and Education, 32, 41-54. http://dx.doi.org/10.1016/j.linged.2015.03.015

Gorski, P.C. (2011). Unlearning deficit ideology and the scornful gaze: Thoughts on authenticating the class discourse in education. Counterpoints, 402, 152-173.

Gotanda, N. (2004). Reflections on Korematsu, Brown and White innocence. Temple Political and Civil Rights Law Review, 13, 663.

Grainger, K., \& Jones, P.E. (2013). The "language deficit" argument and beyond. Language and Education, 27(2), 95-98. https://doi.org/10.1080/09500782.2012.760582

Grosfoguel, R. (2013). The structure of knowledge in westernized universities: Epistemic racism/sexism and the four genocides/epistemicides of the long 16th century. Human Architecture: Journal of the Sociology of Self-knowledge, 11(1), 73-90.

Gunderson, L. (2020). The consequences of English learner as a category in teaching, learning, and research. Journal of Adolescent \& Adult Literacy, 64(4), 431-439. https://doi.org/10.1002/jaal.1116

Gutiérrez, K. (2005/2006). White innocence: A framework and methodology for rethinking educational discourse and inquiry. The International Journal of Learning Annual Review, 12(10), 223-229. https://doi.org/10.18848/1447-9494/CGP/v12i10/48224

Gutiérrez, K.D., \& Orellana, M.F. (2006). The "problem” of English learners: Constructing genres of difference. Research in the Teaching of English, 40(4), 502-507.

Hart, B., \& Risley, T.R. (1995). Meaningful differences in the everyday experience of young American children. Paul H Brookes Publishing.

Hernandez, S.J. (2017). Are they all language learners?: Educational labeling and raciolinguistic identifying in a California middle school dual language program. The CATESOL Journal, $29(1), 133-154$.

Journal of Contemporary Issues in Education, 2021, 16(2), pp. 21-37. 
Heugh, K., \& Stroud, C. (2018). Diversities, affinities and diasporas: A southern lens and methodology for understanding multilingualisms. Current Issues in Language Planning, 20(1), 1-15. http://dx.doi.org/10.1080/14664208.2018.1507543

Hogarth, M. (2017). Speaking back to the deficit discourses: A theoretical and methodological approach. Australian Educational Research, 44, 21-34. https://doi.org/10.1007/s13384017-0228-9

Jones, P.E. (2013). Bernstein's "codes" and the linguistics of "deficit." Language and Education, 27(2), 161-179. http://dx.doi.org/10.1080/09500782.2012.760587

Keating, A. (1995). Interrogating "Whiteness," (de)constructing "race". College English, 57(8), 901-918.

Kloß, S.T. (2017). The global south as subversive practice: Challenges and potentials of a heuristic concept. The Global South, 11(2), 1-17.

Kubota, R. (2020). Confronting epistemological racism, decolonizing scholarly knowledge: Race and gender in applied linguistics. Applied Linguistics, 41(5), 712-732. https://doi.org/10.1093/applin/amz033

Kubota, R., \& Lin, A. (2006). Race and TESOL: Introduction to concepts and theories. TESOL Quarterly, 40(3), 471-493.

Kumaravadivelu, B. (2016). The decolonial option in English teaching: Can the subaltern act? TESOL Quarterly, 50, 66-85. https://doi.org/10.1177/1468798417747029

Kuchirko, Y. (2019). On differences and deficits: A critique of the theoretical and methodological underpinnings of the word gap. Journal of Early Childhood Literacy, 19(4), 533-562.

Lazar, M.M. (2020). "Politics of the South": Discourses and praxis. Discourse \& Society, 31(1), 5-18. https://doi.org/10.1177/0957926519886126

Licea, R. (2020). Is "Latino" useful? Diversity, commonality, and politics. Sociology Compass, 14 (12), 1-13. https://doi.org/10.1111/soc4.12836

Marsh, V.L. (2018). Best practices for educating English language learners: History, controversy, and a path forward. https://www.rochester.edu/warner/cues/wpcontent/uploads/2018/10/ELLS-brief FINAL-.pdf

McIntosh, P. (1989). White privilege: Unpacking the invisible knapsack. http://codeofgoodpractice.com/wp-content/uploads/2019/05/Mcintosh-White-PrivilegeUnpacking-the-Invisible-Knapsack.pdf

McKay, D.L., Vinyeta, K., \& Norgaard, K.M. (2020). Theorizing race and settler colonialism within U.S. sociology. Sociology Compass, 14(9), e12821. https://doi.org/10.1111/soc4.12821

Mignolo, W. (2010). Delinking: The rhetoric of modernity, the logic of coloniality and the grammar of de-coloniality. In W. Mignolo \& A. Escobar (Eds.), Globalization and the Decolonial Option (pp. 303-368). Routledge.

Mitchell, K. (2013). Race, difference, meritocracy, and English: majoritarian stories in the education of secondary multilingual learners. Race Ethnicity and Education, 16(3), 339364. https://doi.org/10.1080/13613324.2011.645569

Moosavi, L. (2020). The decolonial bandwagon and the dangers of intellectual decolonization. International Review of Sociology-Revue Internationale de Sociologie, 30(2), 332-354. https://doi.org/10.1080/03906701.2020.1776919

Journal of Contemporary Issues in Education, 2021, 16(2), pp. 21-37. 
Morita-Mullaney, T. (2018). The intersection of language and race among English learner (EL) leaders in desegregated urban Midwest schools: A LangCrit narrative study. Journal of Language, Identity \& Education, 17(114), 1-17.

Nakata, M. (2007). Disciplining the Savages, Savaging the Disciplines. Aboriginal Studies Press.

Nguyen, K. M. (2021). Limiting labels: Opportunities to learn and college readiness among English language learners. Sociology Compass, 15(2), e12848.

https://doi.org/10.1111/soc4.12848

Ortega, L. (2019). SLA and the study of equitable multilingualism. The Modern Language Journal, 103. https://doi.org/10.1111/modl.12525

Obeyesekere, A. N. (2017). The fairness of shadows: Implications of shadeism on urban secondary school students. In A. Abdulle \& A.N. Obeyesekere (Eds.), New Framings on Anti-racism and Resistance (pp. 1-22). Sense Publishers.

Parakrama, A. (1995). De-hegemonizing language standards: Learning from (post)colonial Englishes about "English." Palgrave.

Patton, D.L., \& Museus, S. (2019). What is deficit thinking? An analysis of conceptualizations of deficit thinking and implications for scholarly research. Currents, 1(1), 117-130. http://dx.doi.org/10.3998/currents.17387731.0001.110

Payne, R.K. (2005). A framework for understanding poverty. Aha! Process, Inc.

Pennycook, A., \& Makoni, S. (2020). Innovations and challenges in applied linguistics from the global south. Routledge.

Pica-Smith, C., \& Veloria, C. (2012). "At risk means a minority kid": Deconstructing deficit discourses in the study of risk in education and human services. Pedagogy and the Human Sciences, 2(1), 33-48.

Pimentel, C. (2011). The color of language: The racialized educational trajectory of an emerging bilingual student. Journal of Latinos and Education, 10(4), 335-353.

http://dx.doi.org/10.1080/15348431.2011.605686

Rosa, J.D. (2016). Standardization, racialization, languagelessness: Raciolinguistic ideologies across communicative contexts. Journal of Linguistic Anthropology, 26(2), 162-183. https://doi.org/10.1111/jola.12116

Rosa, J., \& Flores, N. (2017). Unsettling race and language: Toward a raciolinguistic perspective. Language in Society, 1-27. https://doi.org/10.1017/S0047404517000562

Schornack, M.L. (2019). Whiteness and raciolinguistic ideologies in the preparation of content teachers for working with language-minoritized youth [Unpublished doctoral dissertation]. University of Minnesota.

https://conservancy.umn.edu/bitstream/handle/11299/206385/Schornack_umn_0130E_20 167.pdf? sequence $=1$

Shapiro, S. (2011). Stuck in the remedial rut: Confronting resistance to ESL curriculum reform. Journal of Basic Writing, 30(2), 24-52.

Shapiro, S. (2014). "Words that you said got bigger": English language learners' lived experiences of deficit discourse. Research in the Teaching of English, 48(4), 386-406.

Silverstein, M. (1996). Monoglot "standard" in America: Standardization and metaphors of linguistic hegemony. In D.L. Brenneis \& R.K.S. Macaulay (Eds.), The matrix of language: contemporary linguistic anthropology (pp. 284-306). Westview.

Singhal, M. (2004). Academic writing and Generation 1.5: Pedagogical goals and instructional issues in the college composition classroom. Reading Matrix, 4, 1-13.

Journal of Contemporary Issues in Education, 2021, 16(2), pp. 21-37. 
Solomon, R.P., Portelli, J.P., Danial, B., \& Campbell, A. (2005). The discourse of denial: How white teacher candidates construct race, racism and "white privilege." Race Ethnicity and Education, 8(2), 147-169.

Sousa Santos, Boaventura de. (2014). Epistemologies of the South: Justice against epistemicide. Routledge.

Takaki, N. H. (2020). Exercising southern and decolonial (self)critique in translanguaging: For a juntos stance. Revista X, 15(1), 32-54.

Takayama, K., Heimans, S., Amazan, R., \& Maniam, V. (2016). Doing southern theory: Towards alternative knowledges and knowledge practices in/for education. Postcolonial Directions in Education, 5(1), 1-25.

Takeuchi, M.A. (2021). Geopolitical configuration of identities and learning: Othering through the institutionalized categorization of "English language learners." Cognition and Instruction, 39(1), 85-112. https://doi.org/10.1080/07370008.2020.1825438

Tuhiwai Smith, L. (1999). Decolonizing methodologies: Research and Indigenous peoples. Zed Books.

Umansky, I.M. (2016). To be or not to be EL: An examination of the impact of classifying students as English learners. Educational Evaluation and Policy Analysis, 38(4), 714 737. https://doi.org/10.3102/0162373716664802

Umansky, I., \& Dumont, H. (2021). English learner labeling: How English learner classification in kindergarten shapes teacher perceptions of student skills and the moderating role of bilingual instructional settings. American Educational Research Journal, 58(5), 1-39. https://doi.org/10.3102/0002831221997571

Valencia, R.R. (Ed.). (1997). The evolution of deficit thinking: Educational thought and practice. The Falmer Press.

Veronelli, G. A. (2015). The coloniality of language: Race, expressivity, power, and the darker side of modernity. Wagadu, 13, 108-134.

Viesca, K. (2012). English is not all that matters in the education of secondary multilingual learners and their teachers. International Journal of Multicultural Education, 14(1), 1-21.

Viesca, K. M. (2013). Linguicism and racism in Massachusetts education policy. Education Policy Analysis Archives, 21(52), 1-37. http://epaa.asu.edu/ojs/article/view/977

Von Esch, K., Motha, S., \& Kubota, R. (2020). Race and language teaching. Language Teaching, 53, 391-421. https://doi.org/10.1017/S0261444820000269

wa Thiong'o, N. (1986). Decolonising the mind. James Currey.

Wheeler, R. (2016). "So much research, so little change": Teaching Standard English in African American classrooms. Annual Review of Linguistics, 2(1), 367-390.

Journal of Contemporary Issues in Education, 2021, 16(2), pp. 21-37. 